\title{
The Effects of Product Line Prices and Competitors' Prices on Consumers' Evaluations of Reference Price Advertisements
}

\author{
Yuan-Shuh Lii, Chieh Lun Lin \\ Feng Chia University \\ E-mail address_yslii@fcu.edu.tw, Email address allenlin73@hotmail.com
}

\begin{abstract}
This study presents empirical evidence on the effect of product-line prices and competitors' prices on consumers' price judgments as well as on consumers' use of advertised reference price (A.R.P.) as reference across two product categories. Using a $2 \times 2 \times 2$ factorial design experiment, the findings indicated that consumers did not consider product line prices as an important reference. Competitors' prices were found to be a significant reference in the case of frequently purchased product categories. The moderating roles of product line prices and competitors' prices in reference price advertisements were not found. A.R.P. still exerted the greatest influence on consumers' evaluations of a promotional offer across two product categories.
\end{abstract}

Keywords: advertised reference price, retail pricing strategy, product line prices, competitors' prices

\section{INTRODUCTION}

Reference price advertisements have been extensively practiced in the retail environment and studied by marketing scholars (Kan et al., 2014; Sinha and Adhikari, 2017). These advertisements generally involve a higher price mentioned in an advertising offer to consumers along with a sale price of the product (e.g., regular price $\$ 59.99$, sale price $\$ 47.99$ ). The higher price mentioned in the advertisement is termed as advertised reference price (A.R.P.). Previous studies have revealed that consumers use the A.R.P. as a frame of reference to assess the accompanying sale price. The result of price comparison makes the sale price more appealing and acceptable.

A review of the literature indicates that most of the previous studies in this field were tested in a controlled environment where subjects were only exposed to an advertisement containing an A.R.P. and a sale price (Biswas et al., 1999). However, in a typical purchasing situation, consumers seldom are exposed to only one source of price information. Instead, consumers may encounter a number of prices presented at the point of purchase. All of these prices can potentially be used by consumers as reference(s) for price evaluations. Under this circumstance, the effect of A.R.P. on consumers' price perceptions may be mitigated since consumers may use other sources of price information as a reference to evaluate the A.R.P. and the accompanying sale price. As indicated by Biswas et al. (1999), if consumers do use the other price information presented at the point of purchase to evaluate the reference price advertisement, the deceptive potential of A.R.P. should not be concerned.

Based on the above-mentioned inquiry, the objective of this study is, therefore, to examine whether the presence of other price information at the point of purchase influences consumers' price 
judgments as well as the use of A.R.P. as reference for price evaluations. Findings from such study can help retailers to better understand how consumers react to the A.R.P. and other point-of-purchase price information and hence design a better price communication strategies intended to influence consumers' price perceptions and purchase decisions.

\section{LITERATURE REVIEW}

Rajendran and Tellis (1994) contended that price information presented at the point of purchase is considered as the most immediate and prominent frame of reference relevant to consumers' price perceptions. When consumers have little idea about the price of a given product, or when the purchase occurs spontaneously, price information presented at the point-of-purchase will naturally become an (if not the) reference point for evaluating the value of an offer.

In addition to the A.R.P. that is commonly used by consumers to evaluate the accompanied sale price of a target brand, two other sources of price information, which are typically presented at the point of purchase and can potentially be used by consumers as references for price judgments, are product line prices and competitors' prices.

Product line prices are the prices of a variety of functionally substitutable models within a product line. Consumers may use the product line prices as references for evaluating the price of a particular model in that line. The rationale is that (1) some consumers prefer a specific brand to others and thus use the prices of the specific brand's other models for price evaluations, and (2) some consumers have a tendency to examine the price differential among models within a product line; naturally, the prices of other models will serve as references for price comparisons.

Competitors' prices refer to the prices of other rivalry brands presented at the point of purchase besides the target brand of purchased interest. This is based on the notion that while consumers have no knowledge of a target brand's past prices, they may select any brand available on the current purchase occasion and use its price as a reference for present price judgments. In some circumstances, consumers may use the price of a well-known brand as a reference; in other situations, consumers may simply pick the first brand in the aisle and use its price as a reference. Some recent studies have provided evidence that consumers could respond to competitors' prices relative to other point-ofpurchase price information. Biswas et al. (1999), for example, studied the effects of other brands' prices and semantic cues on consumers' evaluations of reference price advertisements. They found that consumers' evaluations of the deal and search intentions were influenced by other brands' prices. Jacobson and Obermiller (1990) discovered that a brand's expected price was determined by its current price and those of other brands. However, when the current price of the given brand was missing, consumers may thus rely on the price information of other brands to infer the missing price of the given brand.

Since consumers may use either or both of product line prices and competitors' prices as references for price evaluations, the effect of A.R.P. on consumers' price judgments may be mitigated. More specifically, the presence of product line prices and competitors' prices may influence consumers' price perceptions of a specific model within a product line individually and/or jointly, which in turn influences the degree of consumers' reliance on A.R.P. as a reference.

H1: The presence of product line prices has a positive influence on consumers' judgments of (a) the acceptable price range, (b) the most appropriate price, and (c) price fairness of a particular product.

H2: The presence of competitors' prices has a positive influence on consumers' judgments of (a) the acceptable price range, (b) the most appropriate price, and (c) price fairness of a particular product. 
H3: $\quad$ The effect of A.R.P. on consumers' price judgments is moderated by (a) product line prices and (b) competitors' prices.

\section{RESEARCH METHODOLOGY}

The proposed hypotheses were examined in a 2(product line prices: a lower level and higher level) x 2(competitors' prices: a lower level and higher level) x 2(A.R.P.: plausible and implausible) between-subjects design experiment. Subjects were randomly assigned to one of the eight treatment conditions.

\section{Product Stimuli}

Subjects were exposed to two products that are categorized by the frequency of purchase. The frequently purchased product, laundry detergent, and the infrequently purchased product, Blue-ray DVD, were chosen based on the pretest results. Seven brands of Blue-ray DVDs were selected because they appear in every major electronics store in a metropolitan area; they include SONY, PHILIPS, Toshiba, MEMOREX, R.C.A., Panasonic, and JVC. Prices among these brands are very distinct, ranging from $\$ 109.99$ to $\$ 349.95$. Eight brands of laundry detergent were selected on the basis of similarity in size and difference in price; they include Tide, Surf, Western Family, Cheer, Wisk, Arm and Hammer, Xtra, and Era. These brands are very common in every major supermarket. There is a wide variation of prices among these brands, ranging from $\$ 1.99$ to $\$ 7.89$.

\section{Subjects and Procedure}

Subjects were selected to be the average consumers who had the experience(s) of participating in the process of purchasing Blue-ray DVD and laundry detergent. The sampling frame was based upon the residence listings in the White Pages for a major West Coast city in the United States. Systematic sampling was conducted to select 1,200 samples in the telephone directory. Subjects received the survey containing one set of questionnaires by mail.

Assuming that subjects are first exposed to the Blue-ray DVD questionnaire and then to the laundry detergent questionnaire, subjects are first asked to assume that they are now looking at a display for Blue-ray DVD in an electronic store, and they are particularly interested in the SONY Blue-ray DVD. The experimental point-of-purchase display contains price and feature information on the SONY Blue-ray DVD (A.R.P. and advertised sale price), different models of SONY's Blueray DVD (product line prices), and other brands of Blue-ray DVD (competitors' prices). On a separate page, subjects are asked to respond to questions designed to assess their price judgments of the SONY Blue-ray DVD. Subjects then proceed to the next section of the laundry detergent questionnaire.

Of 1,200 consumers responding to the mail survey, 240 valid observations with thirty subjects in each treatment group were obtained. Of those, $43.3 \%$ were women, and $56.7 \%$ were men. Respondents ranged in age from 20 to 71, with a mean of 42.11 years. Most of the respondents had annual incomes of over $\$ 30,000(67.8 \%)$. In terms of formal education, more than half had at least a college degree $(63.4 \%)$. While $64.2 \%$ of the subjects were married, more than half reported at least one dependent. 


\section{Constructs and Measurements}

\section{Independent and Dependent Variables}

Product line prices and competitors' prices were manipulated and presented in a hypothetical display in a retail store containing either a lower or higher level of prices. The manipulation of A.R.P. involved how high a regular price was included in the advertisement at the point of purchase. Two schemes of A.R.P. are commonly studied, namely, plausible and implausible A.R.P.s. While plausible A.R.P. was designed to be reasonably higher than the sale price, the implausible A.R.P. was intentionally manipulated to be exaggeratedly higher than the sale price. Based on the pretests, the plausible A.R.P. was operationalized as a regular price that was about $15 \%$ higher than the sale price for the experimental product. The implausible A.R.P. was operationalized as a regular price that was about $95 \%$ higher than the sale price.

Three dependent variables designed to reflect consumers' price judgments of a particular product are the acceptable price range, the most appropriate price, and price fairness. The acceptable price range is the estimate of the range of prices in which consumers are willing to pay for a product. Using Blue-ray DVD as an example, the acceptable price range was operationalized as the difference between the responses in the following measure. "What would you consider to be an acceptable price range for the SONY Blue-ray DVD?" The most appropriate price was measured by one open-ended question designed to assess a point estimate for the SONY Blue-ray DVD. "What do you think is the most appropriate single price for the SONY Blue-ray DVD?" Price fairness refers to consumers' judgments of whether the stated sale price is honest and fair. It was measured by asking subjects to judge the fairness of the advertised sale price of the SONY Blue-ray DVD.

\section{ANALYSIS AND RESULTS}

An examination of the intercorrelations among all study variables reveals that the three dependent variables were correlated significantly (all $p$ values $<.01$ ). A series of regression analyses were conducted to examine the unique and joint contributions of the product line prices, competitors' prices, and A.R.P. to consumers' price judgments across the two product types. Table 1 shows the regression results.

Table 1. Regression Results of Blue-ray DVD and Laundry Detergent Results of Blue-ray DVD in upper case and Laundry Detergent in lower case

\begin{tabular}{|l|c|c|c|c|c|c|}
\hline \multicolumn{1}{|c|}{ DV } & \multicolumn{2}{|c|}{ The acceptable price range } & \multicolumn{2}{c|}{ The most appropriate price } & \multicolumn{2}{c|}{ Price fairness } \\
\hline \multicolumn{1}{|c|}{ IV } & $\beta$ & $p$-value & $\beta$ & $p$-value & $\beta$ & $p$-value \\
\hline ARP & .297 & .000 & .355 & .000 & .192 & .003 \\
& .182 & .005 & .216 & .001 & .118 & .045 \\
\hline PLP* & .015 & .815 & .122 & .043 & .023 & .715 \\
& .023 & .714 & .038 & .548 & .057 & .373 \\
\hline CP* & .069 & .270 & .094 & .120 & .081 & .208 \\
& .105 & .101 & .161 & .011 & .203 & .002 \\
\hline PLP x ARP & .018 & .872 & .185 & .077 & .141 & .210 \\
& .147 & .176 & .011 & .917 & .068 & .539 \\
\hline CP x ARP & .096 & .358 & .124 & .218 & .149 & .166 \\
& .014 & .900 & .044 & .690 & .015 & .895 \\
\hline PLP x CP & .163 & .145 & .193 & .078 & .206 & .067 \\
& .264 & .058 & .184 & .107 & .062 & .586 \\
\hline PLP x CP x ARP & .071 & .369 & .101 & .184 & .186 & .061 \\
& .107 & .202 & .055 & .509 & .039 & .643 \\
\hline
\end{tabular}

* PLP: product line prices; CP: competitors' prices 
As predicted, A.R.P. had significant impacts on the three price judgment tasks for both product categories. Their influences were also in the direction as predicted (H1 was supported). Only one significant effect was found for the effect of product line prices on consumers' evaluations of the most appropriate price in Blue-ray DVD category. Overall, product line prices did not exert significant influences on consumers' price judgments for both product categories (H2 was not supported). Competitors' prices were found to influence consumers' judgments of the most appropriate price and price fairness in the laundry detergent category. None of the interaction effects was found to support the hypotheses that product line prices and competitors' prices moderate the effect of A.R.P. on consumers' price judgments (H3 was not supported).

\section{DISCUSSION}

This study presents empirical evidence on the referencing and interaction effects of product line prices, competitors' prices, and A.R.P. on consumers' judgments of the acceptable price range, the most appropriate price, and price fairness across two product types. The including of product line price and competitors' prices in this study makes sense because both of them are actually present in a typical point of purchase environment. While most academic research has found that A.R.P. has a significant and positive effect on consumers' evaluations of a promotional offer, the impact of product line prices and competitors' prices on consumers' price judgments for a given product is not clear.

The effect of product line prices was found here to be significant for determining the most appropriate price in the Blue-ray DVD category. This finding weakly supports the conception that the price structure of a product line affects consumers' evaluations of models in that line (Petroshius and Monroe, 1987). Although this effect only occurs in the Blue-ray DVD category, it may imply that consumers could engage in an inter-model price comparison heuristic while buying a product that is infrequently purchased. The absence of the effect of product line prices on other price judgment tasks is consistent with Hoyer's (1984) investigations, where subjects exhibited very little comparison of the same brand's different models in their decision-making process. In the frequentlypurchased product category, the insignificant effect of product line prices may be attributed to consumers' perceptions of product characteristics in which the product differential among models was not sufficiently large enough to attract respondents' attention. In many frequently purchased products (e.g., laundry detergent, toilet paper), the main product differential among models is size and packaging. Consequently, product line prices may not be perceived by consumers as important references for price evaluations.

There has been very little empirical research on the effect of competitors' prices on consumers' price judgments. The evidence suggests that competitors' prices are a significant determination of price judgments in terms of the most appropriate price and price fairness in the case of laundry detergent but not in the case of a Blue-ray DVD. This behavior implies that while respondents had no knowledge of a specific brand's past prices, they used a known brand or any brand available on the current purchase occasion and use its price or prices as reference(s) for present price judgments. This behavior suggests that consumers might employ an inter-brand comparison heuristic (Rajendran and Tellis, 1994) while buying a product that is frequently-purchased.

Given that other researchers fairly consistently report that A.R.P. changes consumers' price perceptions, the observed significant and positive effects of the A.R.P. were expected. The results indicated that the implausible A.R.P. effectively increased the level of the acceptable price range and the most appropriate price than those of the plausible A.R.P. In addition, consumers who were exposed to the implausible A.R.P. judged the advertised sale price to be fairer than those consumers who were exposed to the plausible A.R.P. 
Empirical results did not support the hypothesis that the effect of A.R.P. on consumers' price judgment tasks will be moderated by product line prices and competitors' prices. That is, the effect of A.R.P. on consumers' price judgments did not differ in the presence of other point-of-purchase price information. The insignificant moderating effect may be attributed to the reason that, compared to other point-of-purchase price information, A.R.P. is more relevant and associated with the advertised sale price. In addition, the use of other point-of-purchase price information as reference may require more mental accounting which increases consumers' information load and complicates the price judgment task. As a result, consumers may simply rely on the A.R.P. as a judgmental heuristic to evaluate the sale price in the advertisement.

The test of the differences in the correlation coefficients between the two product types indicated that the effects of product line prices, competitors' prices, and A.R.P. on consumers' price evaluations did not vary between these two product categories. In this case, it seems likely that consumers adopted the same judgmental heuristic to resolve the price evaluation tasks for both product categories.

\section{REFERENCES}

Biswas, Abhijit, Pulling, C., Krishnan, Balaji C., \& Scot Burton (1999). Consumer Evaluation of Reference Price Advertisements: Effects of Other Brands' Prices and Semantic Cues. Journal of Public Policy \& Marketing, 18 (Spring), 52-65.

Hoyer, W. D. (1984). An Examination of Consumer Decision Making for a Common Repeat Purchase Product. Journal of Consumer Research, 11(December), 822-829.

Jacobson, R., \& Obermiller, C. (1990). The Formation of Expected Future Price: A Reference Price for Forward-Looking Consumers. Journal of Consumer Research, 16, 420-432.

Kan, C., Lichtenstein, D. R., Grant, S. J., \& Janiszewski, C. (2014). Strengthening the influence of advertised reference prices through information priming. Journal of Consumer Research, 40(6), 1078-1096.

Petroshius, S. M., \& Monroe, K. B. (1987). Effect of Product-Line Pricing Characteristics on Product Evaluations. Journal of Consumer Research, 13, 511-519.

Rajendran, K. N., \& Tellis, G. J. (1994). Contextual and Temporal Components of Reference Price. Journal of Marketing, 58 (January), 22-34.

Sinha, R.K., \& Adhikari, A. (2017). Advertised reference price and sales price as anchors of the latitude of the expected price and its impact on purchase intention. European Journal of Marketing, 51(9/10), 1597-1611. 